\title{
Parametric analysis of the dynamic characteristics of a long-span three-tower self-anchored suspension bridge with a composite girder
}

\author{
Feifei Shao', Zhijun Chen ${ }^{2}$ and Hanbin Ge 1* $^{*}$
}

\author{
* Correspondence: gehanbin@ \\ meijo-u.ac.jp \\ 'Department of Civil Engineering, \\ Meijo University, Nagoya 468-8502 \\ Japan \\ Full list of author information is \\ available at the end of the article
}

\begin{abstract}
Three-tower self-anchored suspension bridge (TSSB) is more and more favored because of its beautiful structure and strong adaptability to terrain and geological conditions. However, there are few engineering practices and related researches on super long-span three-tower self-anchored suspension bridges. A three-dimensional finite element model for the Fenghuang Yellow River Bridge, with the world's longest span of its kind under construction, is established using the ANSYS finite element program, and the structural dynamic characteristics of the super long-span TSSB are studied and compared with those of several bridges of the same type or with similar spans. In addition, the influence of the key design parameters such as the stiffening girder stiffness, tower stiffness, main cable and suspender stiffness, central buckle, and longitudinal constraint system on the dynamic characteristics of the structure is analyzed. The results show that the first mode of the TSSB is longitudinal floating, the lower-order modes are dominated by vertical bending modes, while the higher-order modes are primarily vibration modes of the main cables, and the torsional modes exhibit strong coupling with the lateral sway of the towers and main cables. The frequency of the first antisymmetric vertical bending mode of the TSSB has an inversely proportional relationship with the main span length. Compared with a double-tower ground-anchored suspension bridge and cable-stayed bridge with similar spans, the TSSB has the lowest frequency for the first antisymmetric vertical bending mode and the highest frequency for the first symmetric vertical bending mode, with a more pronounced coupling with the towers and main cables in the torsional modes. Analysis of the structural parameters shows that the frequencies of the longitudinal floating mode, first antisymmetric vertical bending mode, first symmetric vertical bending mode, and first torsional mode are most sensitive to the longitudinal bending stiffness of the side tower, central buckle, vertical bending stiffness of the stiffening girder, and torsional stiffness of the stiffening girder, respectively. The research findings and relevant conclusions can provide basic data for response analysis of longspan TSSBs under dynamic loads and offer an engineering reference for the design of similar bridges around the world.
\end{abstract}

Keywords: Self-anchored suspension bridge, Three-tower, Composite girder, Dynamic characteristics, Parametric analysis 


\section{Introduction}

Suspension bridges are widely used due to their strong spanning capability, excellent structural performance, and aesthetic advantage. Conventional suspension bridges mostly adopt a ground-anchored structure form, which requires the construction of very large anchorages to secure the main cable, posing a major challenge for construction in poor geological conditions or deep water. Self-anchored suspension bridges (SSBs) have been increasingly favored by the engineering community because of their appealing structural form and strong adaptability to terrain and geological conditions. Although SSBs have some shortcomings in structural efficiency and the construction process, they are still a highly competitive type of bridge in urban construction (Xiao et al. 2016). Some of the well-known SSBs include the Konohana Bridge, with a main span of $300 \mathrm{~m}$, completed in 1990 in Japan (Kamei et al. 1992); the Yeongjong Bridge, with a main span of 300 m, built in 1999 in South Korea (Kim et al. 2002); the New San Francisco-Oakland Bay Bridge, with a main span of $385 \mathrm{~m}$ and a single tower, which opened to traffic in 2013 in the United States (Nader and Maroney 2013); and the Taohuayu Bridge, with a main span of $406 \mathrm{~m}$, completed in 2013 in China. SSBs differ from ground-anchored suspension bridges (GSBs) in terms of the structural system, construction process, and mechanical characteristics. Accordingly, the relevant studies have been focused on these three aspects, for example, the determination of the main cable configuration and a reasonable geometric shape for the bridge upon completion (e.g., Kim et al. 2002; Yong-Gang et al. 2009; Zhou et al. 2019), the analysis of new construction techniques and construction processes (e.g., Lu et al. 2017; Wang et al. 2019, 2020a, 2020b), and the determination of the responses to various dynamic loads, including wind loads (e.g., Li 2019a, 2019b), earthquake loads (e.g., Cheng et al. 2019), and vehicle loads (e.g., Zhou et al. 2017).

At present, most of the SSBs around the world are either single-tower or doubletower systems, while three-tower self-anchored suspension bridges (TSSBs) are rare in engineering practice. Due to the lack of an effective longitudinal constraint on the middle tower, the three-tower system differs significantly from traditional double-tower suspension bridges in terms of structural performance. In recent years, there have been a number of studies on the structural performance of three-tower suspension bridges. In terms of static performance, Yoshida et al. (2004) studied the influence of the stiffening girder stiffness, sag ratio, dead load, etc. on the static deformation characteristics of a three-tower suspension bridge with two $2000 \mathrm{~m}$ main spans by trial design; Jia et al. (2018a, 2018b, 2020) derived simplified formulas for determining the static behavior of a super long-span three-tower GSB and systematically examined the influences of factors such as the sag-to-span ratio, side-to-main-span ratio, middle tower stiffness, girder-height-to-span ratio, girder-width-to-span ratio, and tower-to-girder constraint condition on the static structural performance of the three-tower suspension bridge. In terms of the dynamic characteristics and performance, Wang et al. (2010) investigated the influence of factors such as the stiffening girder stiffness, tower-to-girder constraint condition, and central buckle on the structural dynamic characteristics of three-tower GSBs using the Taizhou Yangtze River Bridge in China as a case example; Wang et al. (2014) and Tao et al. (2018) carried out parametric analysis of the dynamic characteristics to further study the influence of the key structural parameters of three-tower GSBs on the flutter and buffeting performances; Jiao et al. (2017) also used the Taizhou 
Yangtze River Bridge as a case example to investigate the seismic responses of threetower GSBs under random ground motion. However, most studies on three-tower systems take GSBs as the research object, while there is relatively little engineering practice and relevant research on TSSBs. Using the Luozhou Bridge, which is China's first TSSB and has two 168-m-long main spans, as a case example, Zhang and Fang 2013, Zhang et al. 2013, Zhang and Huang 2014) investigated the influence of the middle tower stiffness on the structural dynamic characteristics and seismic performance of the TSSB and studied the seismic responses of the bridge based on shaking table tests and compared the test results with numerical analysis results. Xiao et al. (2016) studied the structural dynamic characteristics, seismic response, and energy dissipation design of another TSSB with six spans and two main spans of $168 \mathrm{~m}$. Kang et al. (2017) carried out parametric analysis of the dynamic characteristics and seismic response of the Binhe Yellow River Bridge in Yinchuan, China, which has two main spans of $218 \mathrm{~m}$ and is currently ranked first in terms of span among all TSSBs in the world. The TSSBs in the above studies all have relatively short spans.

The Fenghuang Yellow River Bridge in Jinan, China, is a TSSB under construction with double cable planes and a composite girder. It has a span arrangement of $70 \mathrm{~m}+$ $168 m+428 m+428 m+168 m+70 m$. After completion, it will set a new world record for TSSBs in terms of span, with an increase from $218 \mathrm{~m}$ to $428 \mathrm{~m}$. Research on the structural performance of such a super long-span TSSB is relatively lacking. In particular, the influence of the key structural parameters on the structural dynamic characteristics, which form an important basis for the structural dynamic responses to, for example, wind and earthquake loads, need to be further clarified. Therefore, in the present study, taking the Fenghuang Yellow River Bridge under construction as the research object, a full-bridge finite element model was built using the ANSYS finite element program to study the structural dynamic characteristics of the super long-span TSSB, and the structural dynamic characteristics were compared with those of several bridges of the same type or with similar spans. In addition, the influence of key design parameters such as the stiffening girder stiffness, tower stiffness, main cable and suspender stiffness, central buckle, and longitudinal constraint system on the structural dynamic characteristics was investigated. The findings of this study can provide a basis for analyzing the responses of long-span TSSBs to dynamic load and offer an engineering reference for the design of similar bridges.

\section{Overview of the case example}

The main bridge of Fenghuang Yellow River Bridge is designed as a TSSB with double cable planes and a composite girder, with a total length of $1332 \mathrm{~m}$. Figure 1 shows the elevation of the main bridge. The stiffening girder is a steel-concrete composite girder with a box section. The girder has a height of $4 \mathrm{~m}$ at the centerline of the road. The standard section has a full width of $61.7 \mathrm{~m}$. The beam of the composite girder is made of Q345qE steel. The concrete deck slab is located in the motor vehicle lanes and the cable area, and it is $12 \mathrm{~cm}$ thick and made of C60 fiber reinforced concrete with low shrinkage. A standard section of the girder in the main span is shown in Fig. 2.

The Fenghuang Yellow River Bridge has three towers, including two side towers and one middle tower. Each tower is designed as an A-shaped structure. The middle tower has a height of $114.58 \mathrm{~m}$ and is seated on a base with a height of $9.09 \mathrm{~m}$, and each side 


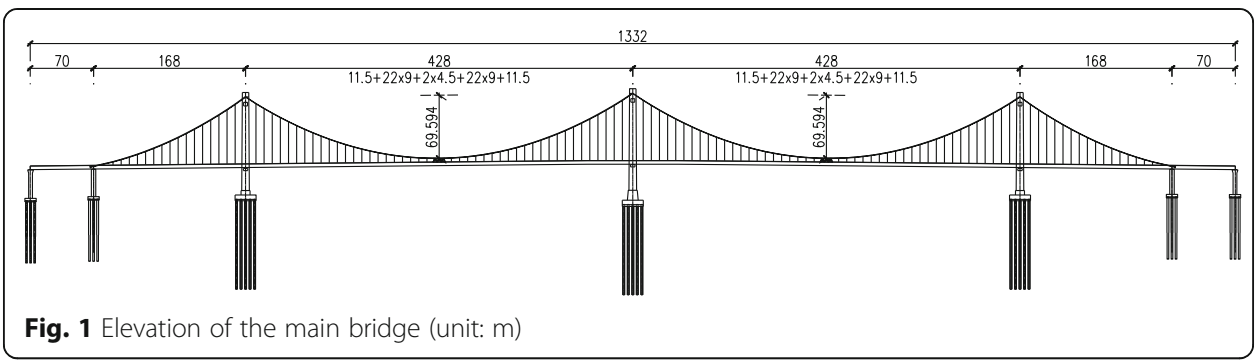

tower has a height of $110.6 \mathrm{~m}$ and is seated on a base with a height of $3 \mathrm{~m}$. The axis of the tower column has a slope of 1:20. The elevation of each tower is shown in Fig. 3. The towers above the bases are all steel structures made of Q420qE steel, and the bases are made of $\mathrm{C} 60$ concrete.

The main cables are the primary load-carrying members of a suspension bridge. The bridge has two main cables, which are arranged into spatial cable planes with a sag-tospan ratio of $1 / 6.15$. Each main cable contains 61 parallel wire strands, each containing 127 wires of $\$ 6.2 \mathrm{~mm}$ galvanized aluminum alloy wire. The suspenders are inclined in the transverse direction and vertical in the longitudinal direction (with a standard spacing of $9 \mathrm{~m}$ ) of the bridge. There are flexible and rigid suspenders. Each flexible suspender consists of $187 \phi 7.0 \mathrm{~mm}$ galvanized aluminum alloy steel wires, and each rigid suspender is made of $\phi 200$ alloy steel $42 \mathrm{CrMo}$.

As the span of the SSBs increases, one of the effective measures to improve the structural stiffness is to install a central buckle at the mid-span to connect the main cables and the stiffening girder. Thus far, this measure has only been used in a small number of long-span GSBs but not in SSBs due to their short overall span. There are three commonly used forms of central buckles: (1) a rigid central buckle, which enables the relative positions of the girder and cables to be fixed at the mid-span and can be implemented by using a rigid triangular truss to connect the main cables and the stiffening girder; (2) a flexible central buckle, which establishes longitudinal constraints on the positions of the girder and cables at the mid-span and can be achieved by adding one or more pairs of diagonal suspender cable at the mid-span; and (3) the direct connection of the main cables to the stiffening girder. A new type of rigid central buckle is adopted for the Fenghuang Yellow River Bridge, with three pairs of central buckle installed at the mid-span of each main span. The bars have a welded I-shaped cross section, and the cable clamp is a cast weld structure consisting of matched upper and lower halves. The bars are installed in three sections. The bars of the central buckle are connected to the upper flange plate of the cable clamp and the top plate of the stiffening girder via M42 high-strength bolts, as shown in Fig. 4.

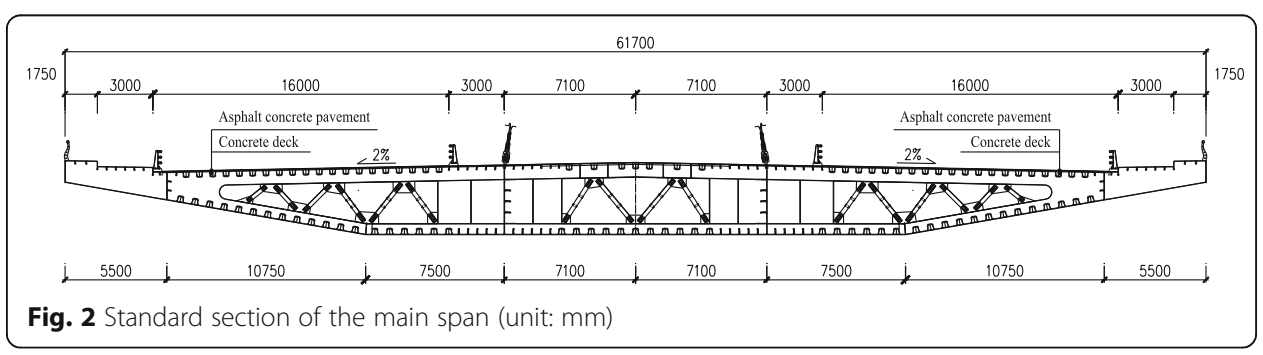




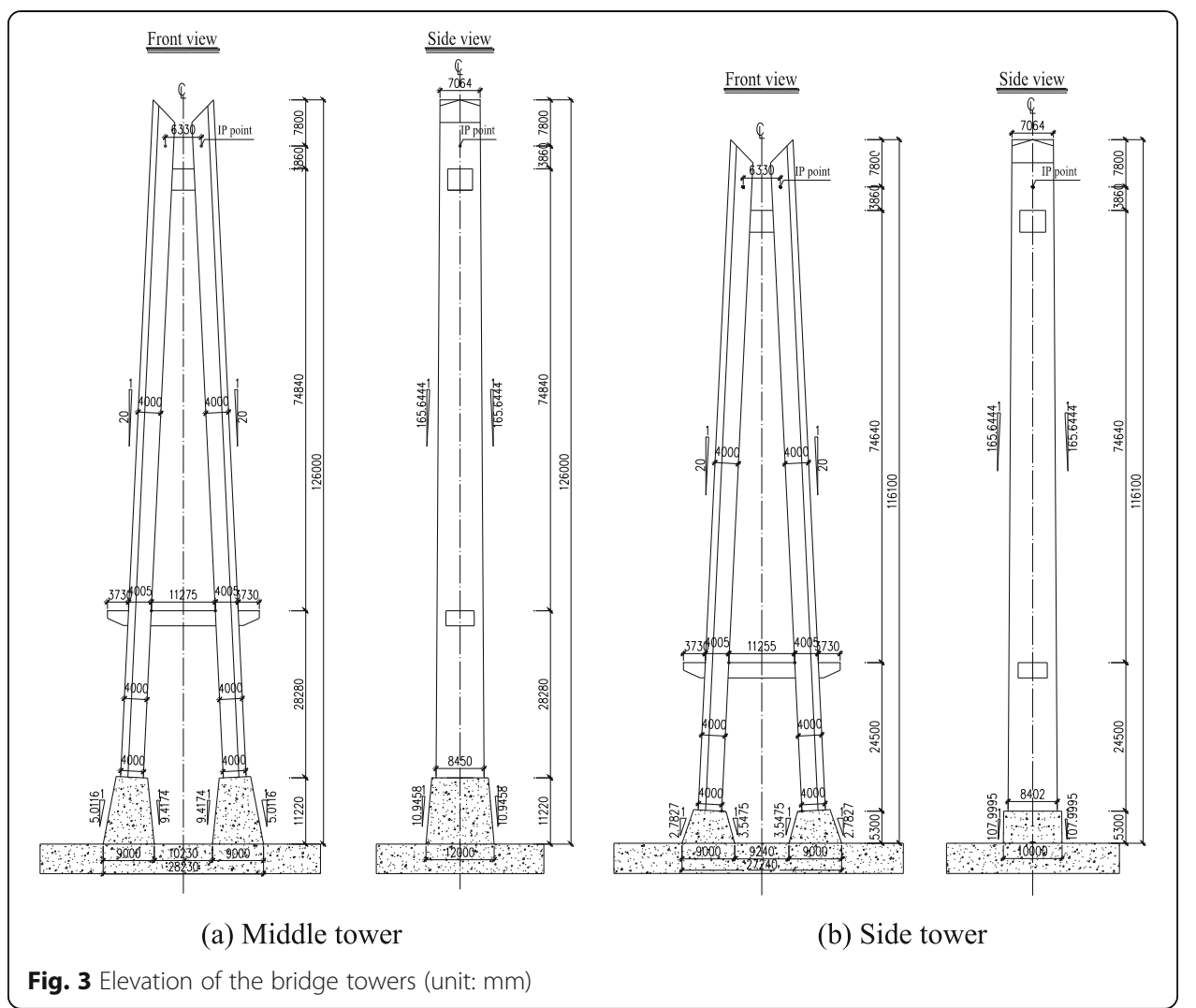

A semi-floating constraint system is adopted for the Fenghuang Yellow River Bridge. In addition to the vertical supports installed at the pier tops and tower-girder connections, longitudinal viscous dampers are installed at the tower-girder connections, and transverse steel dampers are installed at the pier tops and tower-girder connections to meet the requirements for the structural performance under dynamic loads such as earthquakes.

\section{Structural dynamic characteristics}

\subsection{Finite element modeling}

The finite element (FE) model of the Fenghuang Yellow River Bridge was established using ANSYS finite element analysis software, as shown in Fig. 5. The stiffening girder

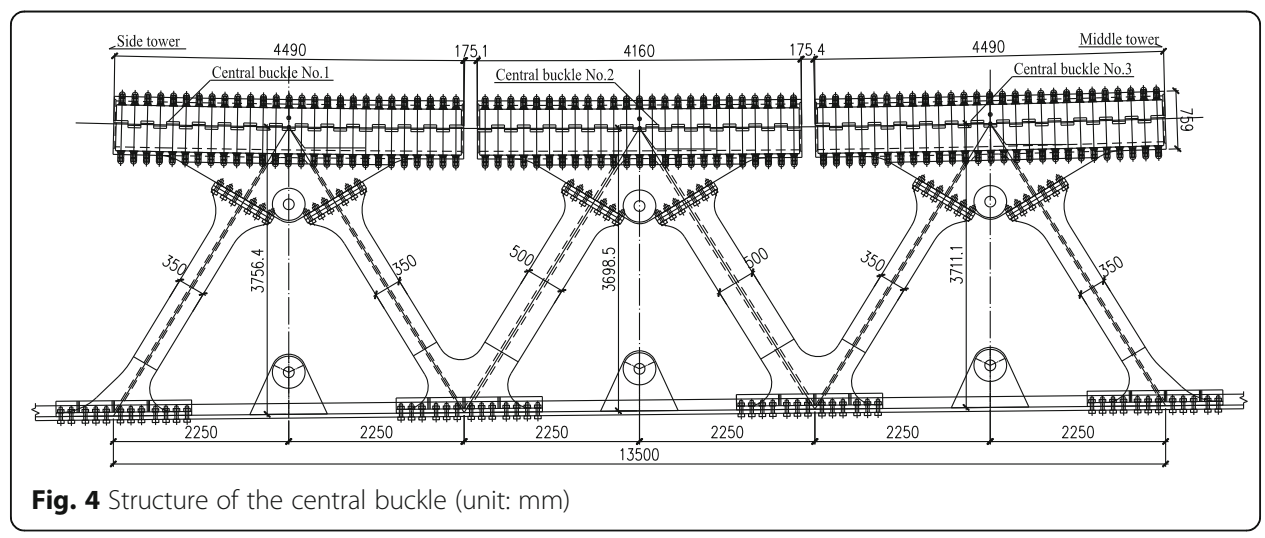




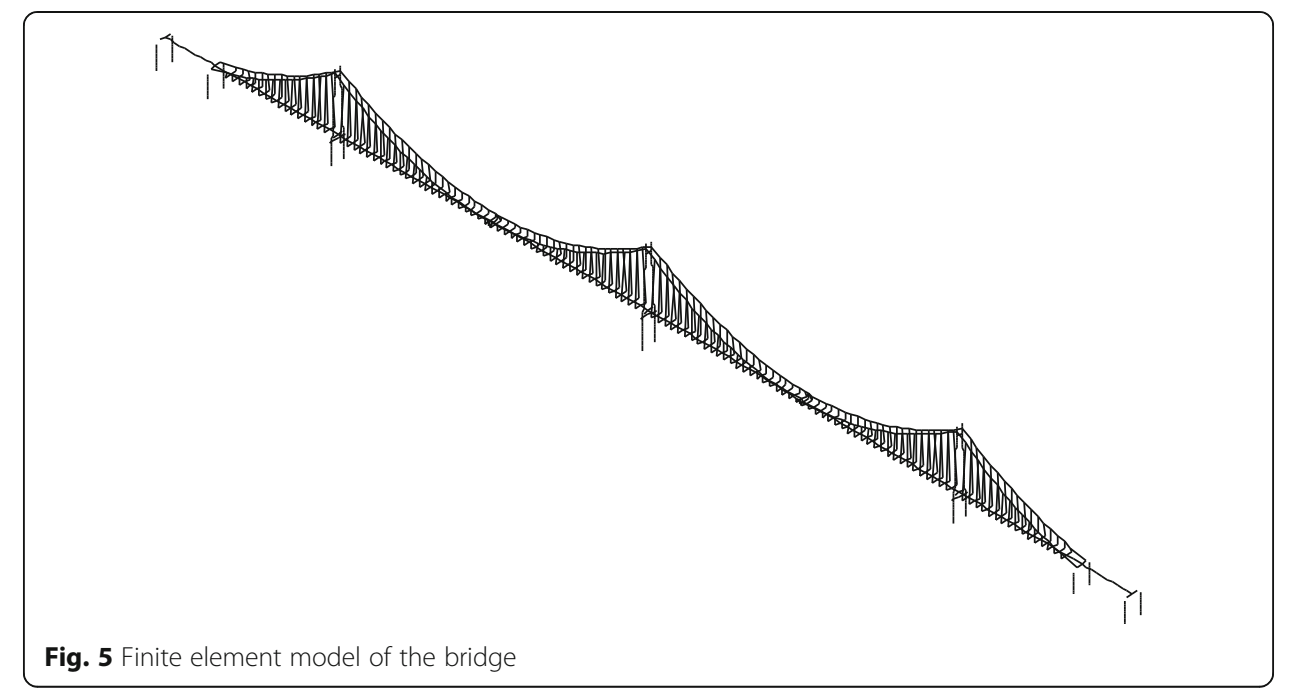

was simulated using a single central spine with offset rigid links to connect the hanging point of the suspender, and the beam element Beam4, having six degrees of freedom at each node, is used. The main towers and piers were also simulated using the beam element Beam4. The main cables and suspenders were simulated by the tension-only bar element Link10. For the modelling of the central buckle, the beam element Beam4 was used. The dead load of the stiffening girder as well as other additional concentrated masses and mass moments of inertia were applied to the relevant nodes using the lumped mass element Mass21. The constraint conditions of the full-bridge finite element model include fixed constraints and master-slave constraints. Specifically, six degree-of-freedom (DOF) fully fixed constraints were adopted at the caps of the towers and piers, ignoring the influence of the pile-soil interaction; the coupling constraints were used between the stiffening girder and towers as well as between the stiffening girder and piers to realize the coupling of vertical and transverse translational DOFs as well as torsional DOFs about the bridge axis; the coupling constraints were also used for the nodes of the main cable and the saddle at the top of the tower to realize the coupling of the three translational DOFs. The anchor end of the main cable was directly connected to the joint of the extended rigid arm of the stiffening girder at the top of the transition pier to form a self-anchored system.

\subsection{Reasonable completion state of the bridge}

The analysis of the structural dynamic characteristics was carried out on the basis of the design state of a bridge upon completion. Generally, the equilibrium state of the bridge under dead load is made to be consistent with the geometric shape design of the bridge upon completion by adjusting the initial strain of the main cables and suspenders. The reasonable geometric shape of the bridge upon completion was determined by the design institute, and the focus of this study was to determine the internal forces of the main cables and the suspenders to make the geometric shape of the bridge approach the target one. In the FE modelling, the reasonable internal forces of the main cables and the suspenders were determined in an iterative way. The horizontal force component of the main cable was taken as an iterative variable. According to the given 
nodal coordinates of the main cables and suspenders, together with the force balance of the joints between the main cable and the suspender, the initial strain of each main cable and suspender element can be obtained. Subsequently, the nodal static displacement can be obtained through the static analysis under dead load. Specifically, with the objective of minimizing the vertical deflection and internal force of the stiffening girder, iterative calculations were performed continuously to ultimately obtain an equilibrium state that was consistent with the geometric shape of the bridge upon completion, i.e., the initial state for dynamic characteristic analysis. Through the adjustment of the initial strain of the main cables and the suspenders, the maximum vertical deflection of the stiffening girder under the final dead load was controlled within $5 \mathrm{~cm}$, as shown in Fig. 6, which meets the accuracy requirement for the calculation of the dynamic characteristics according to a sensitivity analysis of the dynamic characteristics to the cable force.

\subsection{Analysis of the dynamic characteristics}

Based on the FE model under the dead load corresponding to the state of bridge upon completion, the Block Lanczos solver and the consistent mass matrix were used for structural dynamic analysis to obtain the information of the first 100 modes of the bridge. It is found that the frequencies of the first 100 modes are distributed within 2.5 Hz. Table 1 provides a description of the frequencies and mode shapes of the first 20 modes of the bridge. Figure 7 gives the mode shapes of five important modes of the structure. The table and figure show that the first mode of the TSSB is a longitudinal floating mode, which is due to the lack of longitudinal constraints in the FE model. The low-order modes are dominated by vertical bending modes, while the high-order modes tend toward main cable vibration modes. Since a closed steel box girder with a large torsional stiffness is adopted for the stiffening girder, the torsional modes are strongly coupled with the lateral sway of the towers and main cables. In addition, due to the relatively high lateral bending stiffness of the stiffening girder, no lateral bending modes are observed in the first 20 modes.

The structural dynamic characteristics of this long-span TSSB were further compared with those of a TSSB with a total of six spans and two main spans of $168 \mathrm{~m}$ (Xiao et al. 2016), a TSSB with a total of four spans and two main spans of $218 \mathrm{~m}$ (Kang et al. 2017), a double-tower GSB with a main span of $800 \mathrm{~m}$, and a double-tower cablestayed bridge with a main span of $818 \mathrm{~m}$ (Zhang et al. 2012). The comparison results are provided in Table 2.

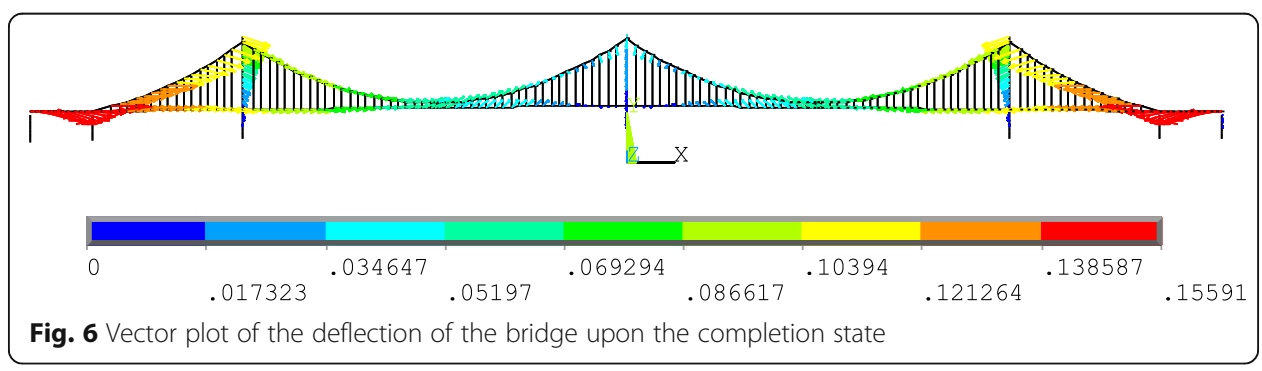


Table 1 Structural dynamic characteristic of the first 20 modes of the bridge

\begin{tabular}{llllll}
\hline $\begin{array}{l}\text { Order of } \\
\text { mode }\end{array}$ & $\begin{array}{l}\text { Frequency } \\
\mathbf{( H z})\end{array}$ & Mode description & $\begin{array}{l}\text { Order of } \\
\text { mode }\end{array}$ & $\begin{array}{l}\text { Frequency } \\
\mathbf{( H z})\end{array}$ & $\begin{array}{l}\text { Mode } \\
\text { description }\end{array}$ \\
\hline 1 & 0.09998 & BD-LG & 11 & 0.52824 & BD-3-SY-V \\
2 & 0.16203 & BD-1-ASY-V & 12 & 0.56296 & MC-SY-L \\
3 & 0.27797 & BD-2-ASY-V & 13 & 0.59849 & MC-ASY-L \\
4 & 0.28202 & BD-1-SY-V & 14 & 0.61127 & MC-ASY-L \\
5 & 0.39176 & BD-2-SY-V & 15 & 0.61130 & MC-SY-L \\
6 & 0.44303 & BD-1-SY-T+BT-SY-L & 16 & 0.61215 & MC-SY-L \\
7 & 0.44715 & BD-1-ASY-T+BT-ASY- & 17 & 0.61229 & MC-ASY-L \\
8 & & L & 18 & 0.62703 & BD-4-ASY-V \\
9 & 0.45514 & BD-3-ASY-V & 19 & 0.65046 & MC-ASY-L \\
10 & 0.47698 & MC-SY-L & 20 & 0.65165 & MC-L \\
\hline
\end{tabular}

Note: $B D$ Bridge deck, $B T$ Bridge tower, MC Main cable, $L G$ Longitudinal, $V$ Vertical, $L$ Lateral, $T$ Torsional, SY Symmetric, ASY Anti-symmetric

A comparison of the dynamic characteristics of the three TSSBs shows the following. The frequency of the first antisymmetric vertical bending mode exhibits a relatively remarkable inversely proportional relationship with the length of the main span. As the span increases, the frequency of the vertical bending mode decreases at a higher rate than that of the torsional mode. Compared with the case of open sections, when the closed steel box girder is adopted for the stiffening girder, the vibration modes of the towers and main cables participate more prominently in the torsional mode, thereby

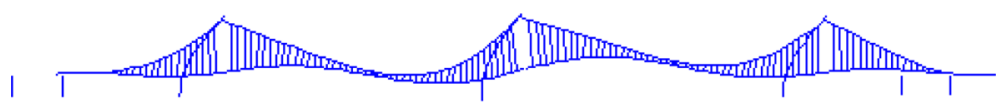

(a) Longitudinal mode

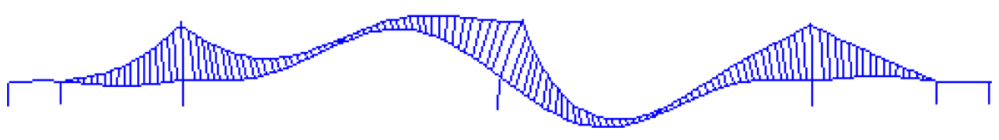

(b) First antisymmetric vertical mode

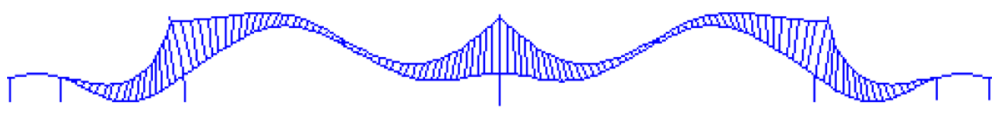

(c) First symmetric vertical mode

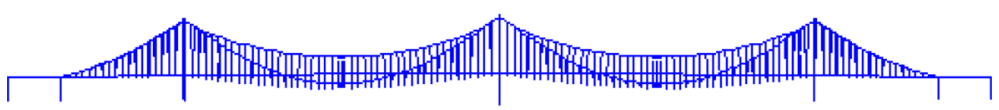

(d) First symmetric torsional mode

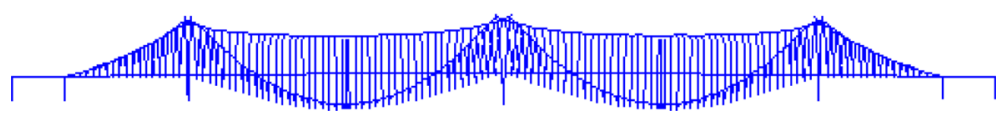

(e) First antisymmetric torsional mode

Fig. 7 Five important mode shapes of the bridge deck 
Table 2 Comparison of the structural dynamic characteristics of bridges of the same type or with similar spans (unit: $\mathrm{Hz}$ )

\begin{tabular}{llllll}
\hline Mode description & TSSB_1 & TSSB_2 & TSSB_3 & DTSB & DTCSB \\
\hline LG & $0.1000(1)$ & $0.201(1)$ & $0.4880(2)$ & $0.1329(3)$ & - \\
BD-1-ASY-V & $0.1620(2)$ & $0.322(2)$ & $0.4084(1)$ & $0.2760(8)$ & 0.3005 \\
BD-2-ASY-V & $0.2780(3)$ & $0.561(5)$ & $0.5603(3)$ & - & - \\
BD-1-SY-V & $0.2820(4)$ & $0.465(3)$ & $0.5605(4)$ & $0.1830(4)$ & 0.2332 \\
BD-2-SY-V & $0.3918(5)$ & $0.554(4)$ & $0.6089(5)$ & - & - \\
BD-1-SY-T & $0.4430(6)$ & $0.727(7)$ & $0.6228(6)$ & $0.3160(10)$ & 0.6103 \\
BD-1-ASY-T & $0.4472(7)$ & $0.570(6)$ & $0.6269(7)$ & $0.5268(26)$ & 0.8207 \\
\hline
\end{tabular}

Bridge description:

TSSB_1: Three-tower six-span self-anchored suspension bridge in the present study

TSSB_2: Three-tower four-span self-anchored suspension bridge with two main spans of $218 \mathrm{~m}$ (composite girder section with two side boxes and openings) (Kang et al. 2017)

TSSB_3: Three-tower six-span self-anchored suspension bridge with two main spans of $168 \mathrm{~m}$ (composite girder section with two side boxes and openings) (Xiao et al. 2016)

DTSB: Double-tower three-span ground-anchored suspension bridge with a main span of $800 \mathrm{~m}$ ( $\pi$-shaped composite girder section with openings) (Li 2019)

DTCSB: Double-tower three-span cable-stayed bridge with a main span of $818 \mathrm{~m}$ (closed steel box girder) (Zhang

et al. 2012)

The numbers in parentheses in the table indicate the orders of the mode

leading to a less significant pattern of variation in the torsional modal frequency with the span length. In addition, the dynamic characteristics of the TSSB in the present study were compared with those of a double-tower suspension bridge and a cablestayed bridge with similar spans from the perspective of comparable spanning capacity. The results show that the frequency of the first antisymmetric mode is the lowest for the TSSB and the highest for the double-tower cable-stayed bridge, while the frequency of the first symmetric vertical bending mode is the lowest for the double-tower suspension bridge and the highest for the TSSB. For the torsional mode, the frequency of the suspension bridge with a single main span is lower than that of the cable-stayed bridge with a single main span, whereas direct comparison of the frequency of the TSSB with that of the former two is not possible since the torsional mode of the TSSB is coupled with strong side sway of the towers and main cables.

\section{Analysis of the influencing parameters on the dynamic characteristics}

Investigation of the influence of key structural parameters on the dynamic characteristics of the TSSB with the largest span at present is of great reference significance for the design of long-span TSSBs. Therefore, using the TSSB in the present study as a case example, the influence of key design parameters such as the stiffening girder stiffness, tower stiffness, main cable and suspender stiffness, central buckle, and longitudinal constraint system on the structural dynamic characteristics was studied. The finite element model in Section 3 was used as the reference model in the analysis.

\subsection{Influence of the stiffening girder stiffness}

The stiffening girder is the main force-resisting member of a TSSB, and changes in its stiffness can directly affect the overall mechanical characteristics of the bridge structure. Since there are no lateral bending modes of the stiffening girder in the first 20 modes of the structure, the influence of the lateral bending stiffness of the stiffening 
girder on the structural dynamic characteristics was not discussed. The influence of the vertical bending stiffness and torsional stiffness of the stiffening girder on the dynamic characteristics was mainly examined. In addition, since the stiffening girder of the TSSB needs to resist not only the bending moment but also the axial compression, the influence of the axial stiffness on the dynamic characteristics of the structure was additionally considered.

The vertical bending stiffness, torsional stiffness, and axial stiffness of the stiffening girder were subject to variation in the range of $\pm 50 \%$ of their respective original values. The adjustment of the stiffness was realized by multiplying the initial stiffness by an amplification factor (i.e. the stiffness coefficient) ranging from 0.5 to 1.5, while the elastic modulus of the material and the mass parameters remained unchanged. Before the parametric analysis of dynamic properties, a sensitivity analysis of the static deflection to stiffness coefficients was carried out to investigate their influence on the completion state of the bridge. It was found that when the maximum (or minimum) stiffness coefficient was applied, the maximum deflection of the stiffening girder changed little. Hence, the input of the initial cable forces was not adjusted during the change of stiffness parameters, performing a parametric analysis with a single variable.

Figure 8 shows the curves of the relationships of the natural frequencies of the key modes of the TSSB structure in the present study and their deviation from their reference frequencies with the three types of stiffness coefficients of the stiffening girder. Frequency deviation in Fig. 8 refers to the rate of frequency change compared to the reference frequency that corresponds to the stiffness coefficient of 1.0.

It can be found in Fig. 8a that the frequencies of the longitudinal floating mode, the first antisymmetric vertical bending mode, and the first symmetric vertical bending mode of the structural system all decrease nonlinearly with decreasing vertical bending stiffness of the stiffening girder. The vertical bending stiffness influences the frequency of the longitudinal floating mode to a relatively small extent but influences the frequency of the first symmetric vertical bending mode the most, especially when the vertical bending stiffness is reduced. When the stiffness coefficient of vertical bending is 0.5 , the frequencies of the first antisymmetric and symmetric vertical bending modes decrease by $16.2 \%$ and $18.5 \%$, respectively. In addition, the calculations show that the vertical bending stiffness has almost no influence on the frequency of the torsional mode of the main girder, thus corresponding results have not been displayed in Fig. 8a. Figure $8 \mathrm{~b}$ shows that there is a nonlinear monotonically increasing relationship between the torsional mode frequency and the torsional stiffness of the stiffening girder. The lower the stiffness is, the faster the torsional mode frequency decreases. The influence on the first antisymmetric torsional mode is greater than that on the first symmetric torsional mode. When the torsional stiffness coefficient is 0.5 , the frequencies of the first symmetric and antisymmetric torsional modes are reduced by $21.3 \%$ and $24.1 \%$, respectively. The calculation also shows that the torsional stiffness has almost no influence on the frequencies of the longitudinal floating and vertical bending modes, which are thus not shown in the figure. In addition, regarding the torsional mode shape, the torsional component of the stiffening girder decreases with the increase of the stiffness coefficient, particularly when the torsional stiffness coefficient is greater than 1.0, and the coupling of the lateral sway of the main cables and towers becomes increasingly prominent. Results in Fig. 8c indicate that although the stiffening girder of the SSB is 


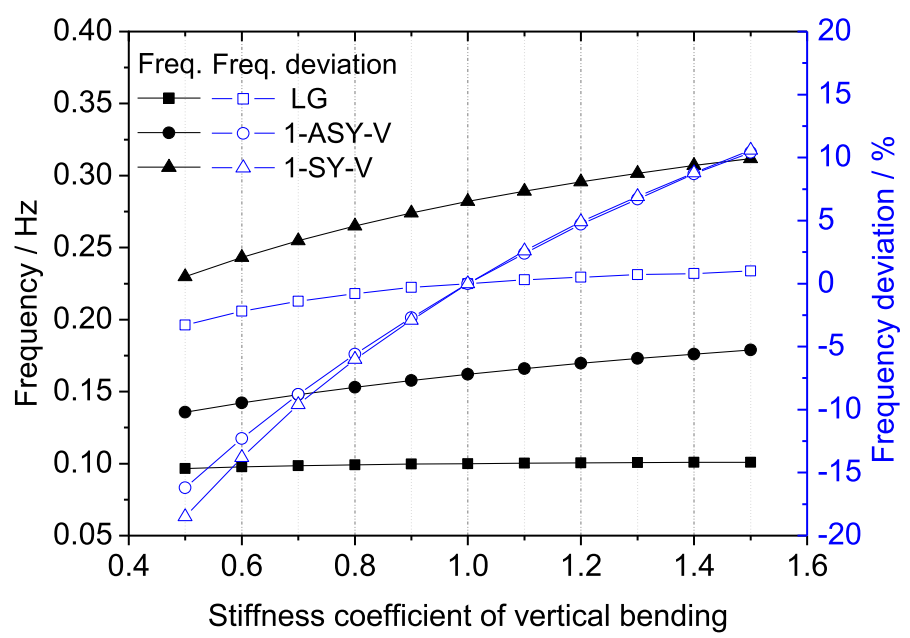

(a) Vertical stiffness

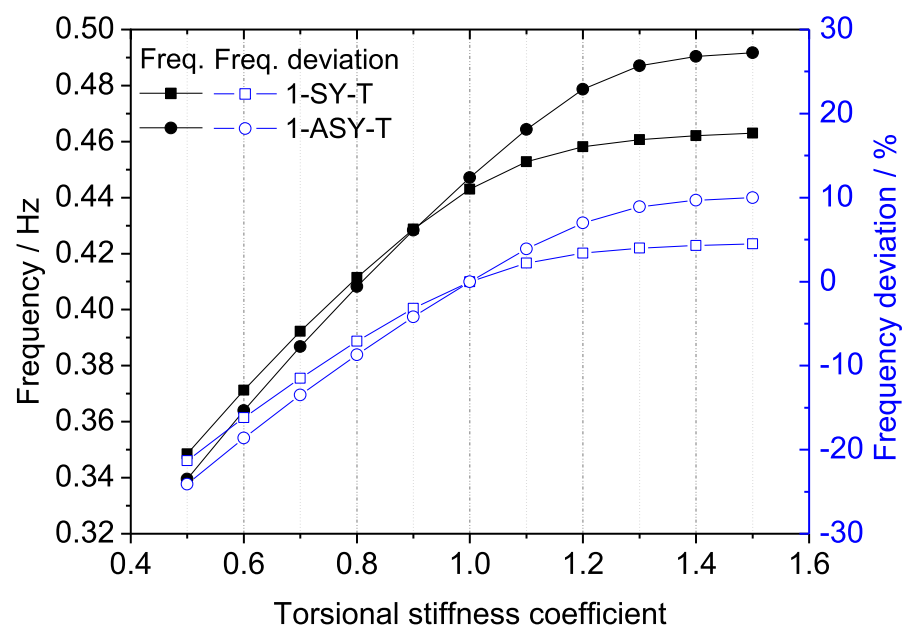

(b) Torsional stiffness

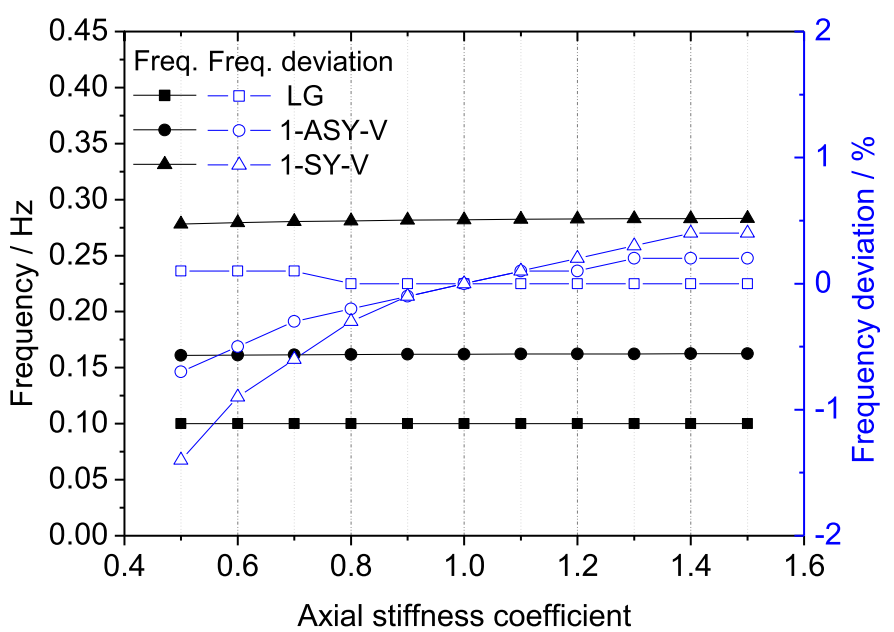

(c) Axial stiffness

Fig. 8 Influence of the stiffening girder stiffness on the natural frequencies of the structure 
subjected to relatively large axial compression, the influence of the axial stiffness on the dynamic characteristics of the structure is very small and can almost be neglected.

\subsection{Influence of the tower stiffness}

Towers are important components of the SSB, especially the middle tower, which is one of the largest differences between the TSSB and single-tower and double-tower structures. Here, the influences of the longitudinal and transverse bending stiffness of the middle tower and side tower of the TSSB on the structural dynamic characteristics were investigated. The adjustment of the stiffness was also realized by multiplying the initial stiffness by the stiffness coefficient ranging from 0.5 to 1.5 , keeping the elastic modulus of the material, the structural masses and boundary conditions remain unchanged. Before the parametric analysis of dynamic properties, a sensitivity analysis of the static deflection to stiffness coefficients, mainly the longitudinal bending stiffness coefficient of the side tower, was carried out to investigate their influence on the completion state of the bridge. It was found that when the maximum (or minimum) stiffness coefficient was applied, the maximum deflection of the stiffening girder changed little. Hence, the influence of the stiffness variation on the completion state of the bridge was ignored. Figure 9 shows the natural frequencies of the important modes of the TSSB under different tower stiffness coefficients and their deviations relative to the reference state.

It can be found in Fig. 9a that with the increase of longitudinal bending stiffness of the towers, the frequencies of the longitudinal floating mode and the first vertical bending mode increase approximately linearly, and the longitudinal floating mode is influenced the most. In addition, the influence of the side tower stiffness is greater than that of middle tower stiffness. The longitudinal stiffness coefficient of 0.5 corresponds to a decrease of $24.8 \%$ in the frequency of the longitudinal floating mode, which is mainly because that the longitudinal floating mode corresponds to the longitudinal bending oscillation of the three towers, and the two side towers contribute substantially to the total stiffness. The influence on the first antisymmetric vertical bending mode is contributed predominately by the longitudinal stiffness of the middle tower with minimal contribution from the side tower stiffness, and the influence on the first symmetric vertical bending mode is the opposite. This can also be explained by the mode shapes shown in Fig. 7b,c. Since the transverse bending stiffness of the tower has almost no influence on the longitudinal floating and vertical bending modes, Fig. $9 \mathrm{~b}$ shows only the variation curves of the torsional mode frequency. As seen from the figure, the transverse stiffness of the side tower has little influence on the torsional mode frequency and can nearly be neglected. The middle tower has little or no influence on the first antisymmetric torsional mode, whereas as the stiffness of the middle tower decreases, the frequency of the first symmetric torsional mode decreases at an accelerated rate. Combined with the mode shape analysis, as the transverse stiffness coefficient decreases, the torsional mode component of the main girder in the symmetric torsional mode almost disappears and gradually turns into the lateral sway of the towers and main cables, while the relatively pure torsional modes migrate to higher orders and the corresponding mode shapes change.

\subsection{Influence of the cable tensile stiffness}

By means of variation in the material elastic modulus of cables and suspenders while keeping the other structural parameters constant, the relationship between the 

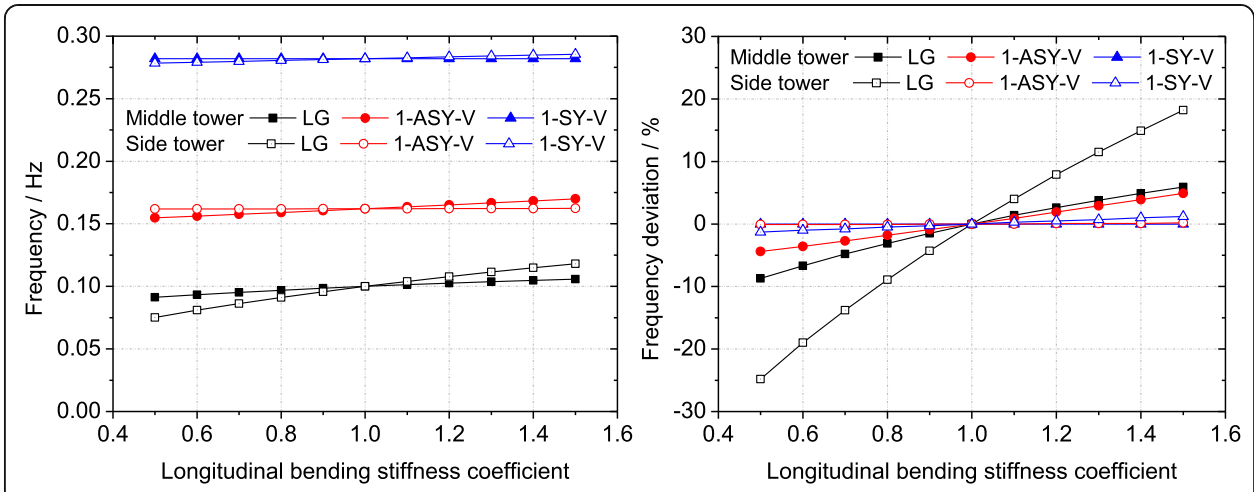

(a) Longitudinal bending stiffness
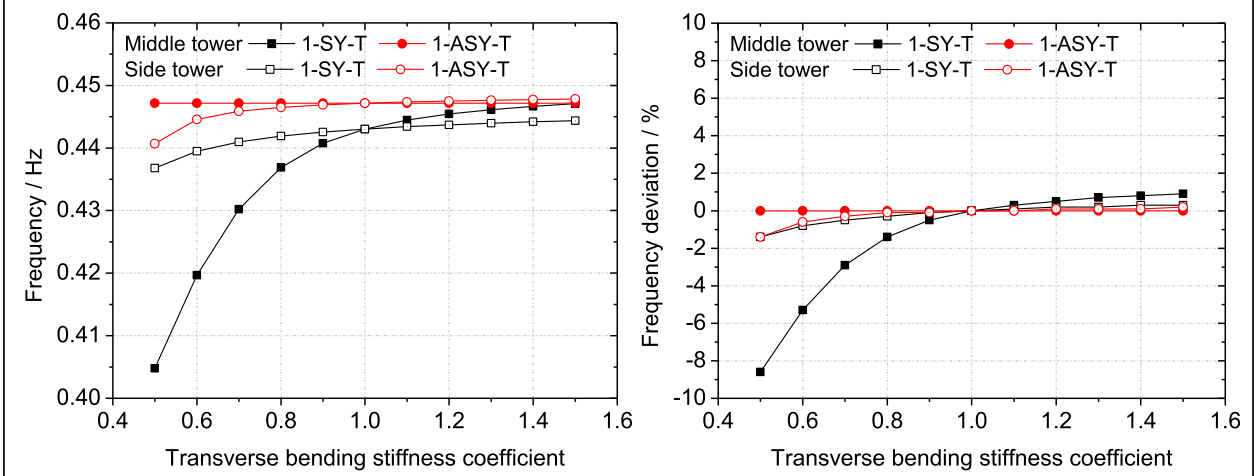

(b) Transverse bending stiffness

Fig. 9 Influence of the tower stiffness on the natural frequencies of the structure

structural dynamic characteristics of the TSSB and its cable tensile stiffness is investigated. During the parametric analysis of the cable and suspender stiffness, the initial input of the main cable force was not changed, so that the geometric shape of the bridge would change to some extent with the variation of the cable tensile stiffness. A sensitivity analysis of the dynamic characteristics to the initial cable force was conducted before the parametric analysis. It was found that the initial force of the main cable that changed within a certain range had little effect on the dynamic characteristics of the structure. Therefore, the influence of change in cable tensile stiffness on the geometric shape of the bridge was ignored in this study for the sake of simplicity. The stiffness coefficients vary in the range of 0.5 to 1.5 . Figure 10 shows the natural frequencies of the important modes of the TSSB under different axial stiffness of the main cables and suspenders, and their deviations relative to the reference state.

Figure 10a shows that as the axial stiffness of the main cable increases, the frequencies of the main modes of the structure increase nonlinearly. The influence on the frequency of the vertical bending mode is the strongest, followed by that on the frequency of the torsional mode, and that on the frequency of longitudinal floating mode is the weakest. With a stiffness coefficient of 0.5 , the frequencies of the first antisymmetric and symmetric vertical bending mode decrease by $9.7 \%$ and $13.6 \%$, respectively. As seen in Fig. 10b, increasing tensile stiffness of the suspender has a very small influence on the modal frequency in all directions of the structure, with a variation amplitude of less than $1 \%$, indicating that suspenders act only as important load transfer members in the suspension bridge system and have little influence on the stiffness of the system. 

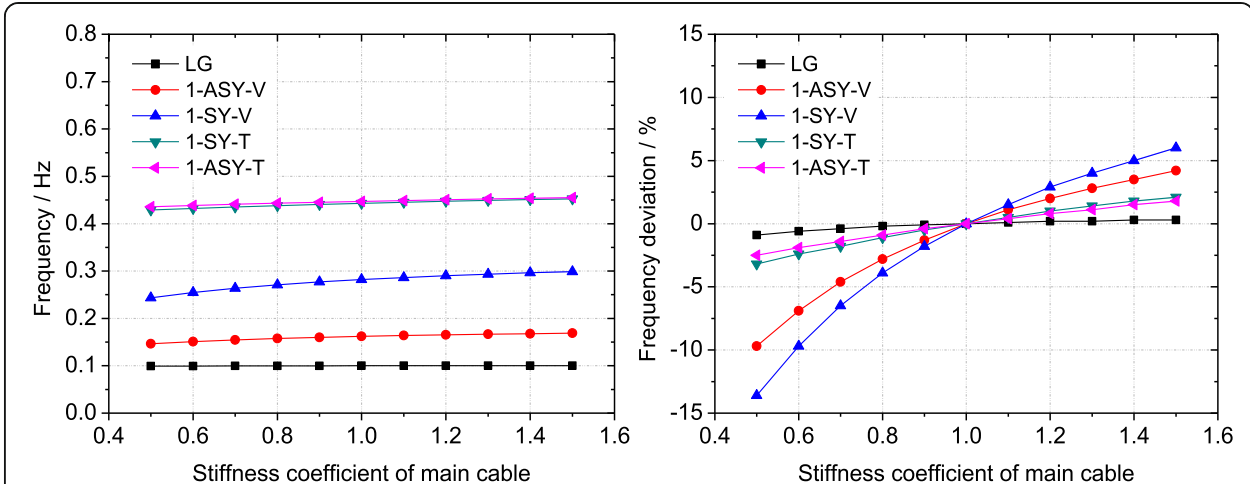

(a) Main cable
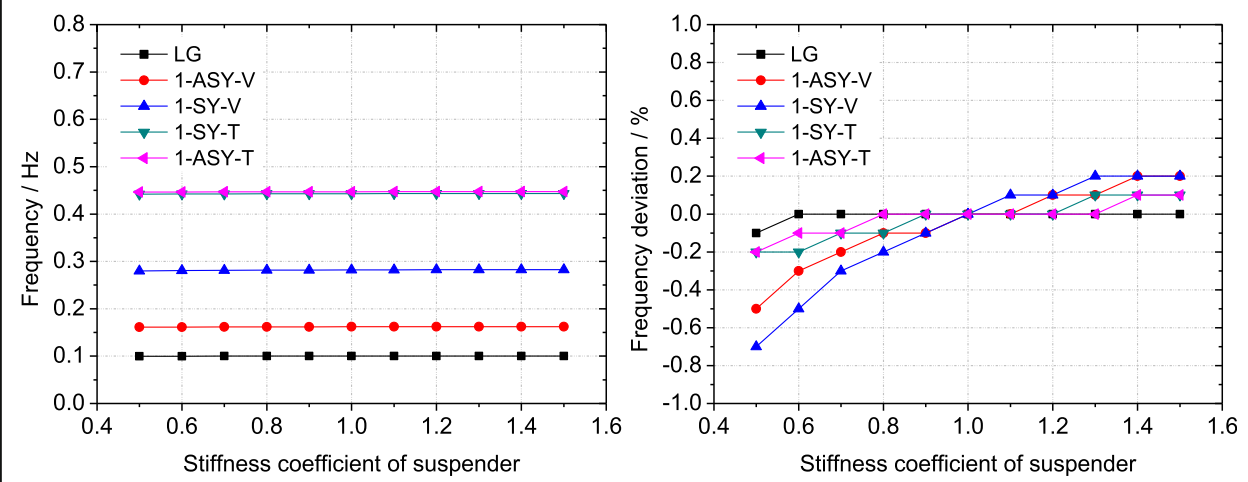

(b) Suspender

Fig. 10 Influence of the cable axial stiffness on the natural frequencies of the structure

\subsection{Influence of the central buckle}

The rigid central buckle at the mid-span was replaced with three rigid suspenders, and the dynamic characteristics of the structure were recalculated. Table 3 compares the frequencies and mode shapes of the important modes of the structure with and without the central buckle, respectively. As seen from the table, after removal of the central buckle, the key mode shapes do not change significantly, but the natural frequencies of the longitudinal floating and vertical bending modes both decrease, and in particular, the frequency of the first antisymmetric vertical bending mode decreases by as much as $21.7 \%$, indicating that the extent of influence exceeds that when the stiffness coefficients of the stiffening girder and tower are 0.5. Therefore, as the span of the TSSB increases, the vertical bending stiffness of the system decreases sharply (Table 2), and the rigid central buckle can be used to effectively increase the vertical bending stiffness of the system. In addition, Table 3 shows that the central buckle essentially has no influence on the torsional mode frequency.

\subsection{Influence of the longitudinal constraint system}

To study the influence of the longitudinal constraint system at the tower-girder connections on the dynamic characteristics of the structure, the longitudinal DOFs at the middle tower-girder connection were coupled; the corresponding results are compared in Table 4 with those obtained by the reference FE model with a complete release of 
Table $\mathbf{3}$ Influence of the central buckle on the dynamic characteristics of the structure

\begin{tabular}{|c|c|c|c|c|c|}
\hline \multirow{2}{*}{$\begin{array}{c}\text { Mode } \\
\text { Description }\end{array}$} & \multicolumn{2}{|r|}{ (1) With central buckle } & \multicolumn{2}{|r|}{ (2) Without central deduction } & \multirow{2}{*}{$\begin{array}{l}\text { (2)/(1)-1 } \\
(\%)\end{array}$} \\
\hline & $f(\mathrm{~Hz})$ & Mode Shape & $f(\mathrm{~Hz})$ & Mode shape & \\
\hline LG & 0.09998 & $\Delta$ & 0.09025 & $x_{+}$ & -9.7 \\
\hline $1-\mathrm{ASY}-\mathrm{V}$ & 0.16203 & & 0.12692 & & -21.7 \\
\hline $1-\mathrm{SY}-\mathrm{V}$ & 0.28202 & & 0.27088 & & -4.0 \\
\hline 1-SY-T & 0.44303 & 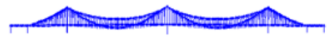 & 0.44250 & 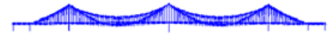 & -0.1 \\
\hline 1-ASY-T & 0.44715 & 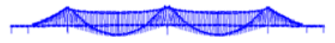 & 0.44600 & 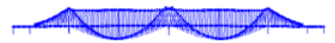 & -0.3 \\
\hline
\end{tabular}

longitudinal constraints. With the addition of the longitudinal constraint, the longitudinal floating mode disappears, which has a direct influence on the longitudinal seismic response. In addition, the frequencies of the other main modes remain almost unchanged.

\section{Conclusions}

In the present study, taking the Fenghuang Yellow River Bridge, which has the largest main span among TSSBs in the world, as a case example, the dynamic characteristics including the frequencies and mode shapes were investigated and compared with those of bridge structures of the same type or with similar spans. Sensitivity analysis of the dynamic characteristics of the TSSB to structural parameters was also carried out. The following main conclusions can be drawn:

(1). The frequencies of the first 100 modes of the TSSB are all distributed within 2.5 $\mathrm{Hz}$. The first mode is longitudinal floating, the lower-order modes are dominated by vertical bending modes, and the higher-order modes are primarily main cable vibration modes. The fundamental torsional modes are strongly coupled with the lateral sway of the towers and main cables. Since the bridge has a relatively large width-to-span ratio, lateral bending modes are not observed in the first 20 modes.

(2). Comparison of the dynamic characteristics of three TSSBs shows that the frequency of the first antisymmetric vertical bending mode exhibits a relatively good inversely proportional relationship with the main span. Compared with the case of open deck section, when a closed steel box girder is adopted, the lateral sway of the towers and main cables become more prominent in the torsional

Table 4 Influence of longitudinal constraints on the dynamic characteristics of the structure (units: $\mathrm{Hz}$ )

\begin{tabular}{llllll}
\hline $\begin{array}{llll}\text { Mode } \\
\text { Longitudinal constraint }\end{array}$ & LG & $\begin{array}{l}\text { 1-ASY- } \\
\text { V }\end{array}$ & 1-SY-V & 1-SY-T & \multicolumn{1}{c}{$\begin{array}{l}\text { 1-ASY- } \\
\text { T }\end{array}$} \\
\hline Released & 0.09998 & 0.16203 & 0.28202 & 0.44303 & 0.44715 \\
Enforced & None & 0.16203 & 0.28202 & 0.44303 & 0.44825 \\
\hline
\end{tabular}


modes, and hence, there are no obvious laws of variation in the torsional mode frequencies with the span.

(3). A comparison of the dynamic characteristics of the TSSB with those of a doubletower suspension bridge and cable-stayed bridge with similar spans shows that the frequency of the first antisymmetric vertical bending mode is the lowest for the TSSB and the highest for the double-tower cable-stayed bridge. The frequency of the first symmetric vertical bending mode is the lowest for the double-tower suspension bridge and the highest for the TSSB. For the torsional mode frequency, since the lateral sways of the towers and main cables are strongly coupled in the torsional modes of the TSSB, which is different from the double-tower suspension bridge and cable-stayed bridge, a comparison of the torsional mode frequencies does not reveal obvious laws of variation.

(4). The parametric analysis of the main girder, towers, and main cables shows that as the stiffness decreases, the frequencies of the relevant modes generally decrease nonlinearly and the sensitivity of the frequencies to the structural parameters increases. In addition, the longitudinal floating mode is influenced the most by the longitudinal bending stiffness of the side tower, the frequency of the first vertical bending mode is influenced the most by the vertical bending stiffness of the stiffening girder, and the frequency of the first torsional mode is the most sensitive to the torsional stiffness of the stiffening girder.

(5). The central buckle significantly influences the frequency of the first antisymmetric vertical bending mode. The addition of the center buckle can effectively improve the vertical bending stiffness of the TSSB. The change in the natural frequency of the structure after the addition of longitudinal constraints at the middle tower is almost negligible, but the disappearance of the longitudinal floating mode may deteriorate the seismic performance. Therefore, it is recommended that the longitudinal constraints be released.

\section{Abbreviations}

TSSB: Three-tower self-anchored suspension bridge; DOF: Degree-of-freedom

Acknowledgements

The authors would like to thank the reviewers for their many constructive comments and suggestions.

Authors' contributions

Authors' contributions to this work are shown below: Feifei Shao: Analysis, Writing - Original Draft. Zhijun Chen: Conceptualization; Methodology. Hanbin Ge: Supervision; Writing - Review \& Editing. The authors read and approved the final manuscript.

Funding

Not applicable.

\section{Availability of data and materials}

The datasets used and analyzed during the current study are available from the corresponding author on reasonable request.

Competing interests

The authors declare that they have no competing interests.

\section{Author details}

${ }^{1}$ Department of Civil Engineering, Meijo University, Nagoya 468-8502, Japan. ${ }^{2}$ School of Civil and Hydraulic Engineering, Huazhong University of Science and Technology, Wuhan 430074, China. 
Received: 26 August 2020 Accepted: 18 September 2020

Published online: 27 September 2020

\section{References}

Cheng YY, Zhang J, Wu JJ (2019) Fragility analysis of a self-anchored suspension bridge based on structural health monitoring data [J]. Adv Civil Eng 2019:Article ID 7467920. https://doi.org/10.1155/2019/7467920

Jia LJ, Lin ZB, Xiao RC, Jiang Y (2018b) Parameter effects on the mechanical performance of triple-tower four-span suspension bridges [J]. Adv Struct Eng 21(2):256-269

Jia LJ, Wang JL, Jiang Y, Xu R (2020) A parametric study of long-span triple-tower suspension bridge [J]. Adv Struct Eng. https://doi.org/10.1177/1369433220931210

Jia LJ, Zhang C, Jiang Y, Cheng J, Xiao RC (2018a) Simplified calculation methods for static behaviors of triple-tower suspension bridges and parametric study [J]. Int J Steel Struct 18(2):685-698

Jiao CK, Dong X, Li AQ, Zhou GD, Wu XP (2017) Seismic response of long-span triple-tower suspension bridge under random ground motion [J]. Math Probl Eng 2017:1-16. https://doi.org/10.1155/2017/3457452

Kamei M, Maruyama T, Tanaka H (1992) Konohana bridge, Japan [J]. Struct Eng Int 2(1):4-6

Kang JT, Hu J, Dong PD, Cao HY, Shao GQ, Qin SQ (2017) Parametric analysis of dynamic performance of triple-tower selfanchored suspension bridge [J]. J Wuhan Univ Technol (Transport Sci Eng) 41(4):543-548 (In Chinese)

Kim HK, Lee MJ, Chang SP (2002) Non-linear shape-finding analysis of a self-anchored suspension bridge [J]. Eng Struct 24(12):1547-1559

Li LY (2019a) Analysis of uncertainty influence on the probabilistic evaluation of vortex-induced vibration response of a selfanchored suspension bridge [J]. KSCE J Civ Eng 23(11):4790-4799

Li SS (2019b) Research on the static and dynamic characteristics and torsional effect of long-span suspension bridges with spatial cable system [D]. Chengdu, Southwest Jiaotong University (In Chinese)

Lu PZ, Shao H, Cheng JT (2017) Computational method for determining the mechanical tension in a self-anchored suspension bridge during construction and its engineering application [J]. Eng Comput 34(5):1468-1484

Nader M, Maroney B (2013) The new San Francisco-Oakland Bay bridge [C]. In: Structures Congress

Tao TY, Wang H, Wu T (2018) Parametric study on buffeting performance of a long-span triple-tower suspension bridge [J]. Struct Infrastruct Eng 14(3):381-399

Wang H, Tao TY, Zhou R, Hua XG, Kareem A (2014) Parameter sensitivity study on flutter stability of a long-span triple-tower suspension bridge [J]. J Wind Eng Industr Aerodynamics 128:12-21

Wang H, Zou KG, Li AQ, Jiao CK (2010) Parameter effects on the dynamic characteristics of a super-long-span triple-tower suspension bridge [J]. J Zhejiang Univ-Sci A 11(5):305-316

Wang XM, Fei PB, Doug Y, Wang CS (2019) Accelerated construction of self-anchored suspension bridge using novel towergirder Anchorage technique [J]. J Bridg Eng 24(5):05019006

Wang XM, Wang H, Sun Y, Mao XY, Tang SP (2020b) Process-independent construction stage analysis of self-anchored suspension bridges [J]. Autom Constr 117:103227

Wang XM, Wang XD, Doug Y, Wang CS (2020a) A novel construction Technology for Self-Anchored Suspension Bridge Considering Safety and Sustainability Performance [J]. Sustainability 12(7):2973

Xiao W. Wang ZQ, Wei HY (2016) Seismic response analysis of self-anchored suspension bridge with multi-tower [J]. Int J Steel Struct 16(4):1329-1338

Yong-Gang T, Feng G, Zhe Z (2009) Analytical method for main cable configuration of two-span self-anchored suspension bridges [J]. Struct Eng Mech 32(5):701-704

Yoshida O, Okuda M, Moriya T (2004) Structural characteristics and applicability of four-span suspension bridge [J]. J Bridge Eng, ASCE 9(5):453-463

Zhang C, Chen YJ, Fang ZZ, Wu SP (2013) Influence law of middle tower on mechanical performance of three-tower selfanchored suspension bridge [J]. Adv Mat Res 684:134-138

Zhang C, Fang ZZ (2013) Shaking table test of multi-tower self-anchored suspension bridge [J]. Appl Mech Mater 353-354: $2216-2220$

Zhang C, Huang K (2014) Influence law of tower stiffness on vertical stiffness of three-tower self-anchored suspension bridge based on frequency formulas [J]. J Vibroeng 16(6):2908-2919

Zhang KG, Yang YX, Zhang JF, Dong R (2012) Sectional model wind tunnel tests and wind-induced static instability analysis of long-span cable-stayed bridges [J]. J Shenyang Jianzhu Univ (Natural Science) 28(4):584-591 (In Chinese)

Zhou GP, Li AQ, Li JH (2019) Determination and implementation of reasonable completion state for the self-anchored suspension bridge with extra-wide concrete girder [J]. Appl Sci-Basel 9(12):2576

Zhou GP, Li AQ, Li JH, Duan MJ (2017) Test and numerical investigations on static and dynamic characteristics of extra-wide concrete self-anchored suspension bridge under vehicle loads [J]. J Cent South Univ 24(10):2382-2395

\section{Publisher's Note}

Springer Nature remains neutral with regard to jurisdictional claims in published maps and institutional affiliations. 